\title{
A (Des) Ordem Na Busca De Um "Real" Progresso: Um Olhar Sobre as Manifestações Brasileiras
}

\author{
Jonatan de Jesus Gomes ${ }^{1}$ \\ Jonatan.jesus99@yahoo.com.br \\ Lazaro Penha ${ }^{1}$ \\ lazaropenha@hotmail.com \\ Priscilla Abrantes da Silva ${ }^{1}$ \\ priscillabrantes@gmail.com \\ Ricardo Alves dos Santos ${ }^{1}$ \\ rixa.alves@gmail.com
}

\section{Resumo}

Este ensaio é fruto das reflexões da disciplina de Espaço Brasileiro III, e de uma grande inquietação acerca de um dos maiores acontecimentos do Brasil nos últimos 30 anos: as manifestações ocorridas ao longo do ano de 2013, e a insatisfação com o "progresso" e a "democracia" brasileira, que sustentam as demandas de um sistema econômico excludente e segregador, e que só existe na prática para os grupos sociais de alta renda.

Palavras-chaves: Ativismo; lugar; direito à cidade; crise das representações.

\footnotetext{
${ }^{1}$ Universidade do Estado do Rio de Janeiro

Faculdade de Educação da Baixada Fluminense
} 


\section{Resume}

Este ensayo es el resultado de las reflexiones de la disciplina de la brasileña Espacio III, y una gran preocupación por uno de los mayores eventos en Brasil durante los últimos 30 años: las manifestaciones ocurrieron durante todo el año 2013, y la insatisfacción con el "progreso" y "democracia "en Brasil, el sostener las demandas de un sistema económico segregado y excluyente, y que sólo existe en la práctica para los grupos sociales de alta renta.

\section{Palabras - claves}

Activismo, el lugar, el derecho a la ciudad, la crisis de la representación.

\section{Introdução}

Tendo em vista os últimos acontecimentos que ocorreram no Brasil ao longo do ano de 2013, o presente trabalho busca elucidar como o ato de manifestar pode proporcionar mudanças significativas na construção de um espaço menos desigual. E como o âmbito do lugar e a participação popular se tornam um elo importante na busca do direito de se pensar a "mudança" e na transformação da sociedade.

A partir da perspectiva de crise das representações de ENAUDEAU² (1999) e de suas simbologias, derivadas da sociologia Weberiana; das indagações presentes na obra $\mathrm{V}$ de Vingança de Alan Moore ${ }^{3}$ (1985); da compreensão de força do lugar de Milton Santos (1996); e da importância que os atores sociais adquirem nesse processo,

\footnotetext{
${ }^{2}$ Professora de filosofia no Liceu Henri IV em Paris e no Lycée Janson-de-Sailly. Foi diretora do programa no Colégio Internacional de Filosofia (2001-2007).

${ }^{3}$ Autor britânico de histórias em quadrinhos
} 
tornando-se instrumentos de transformação da realidade, como destaca Ferreira ${ }^{4}$ (2007). Busca-se ao longo deste ensaio compreender a expressão geográfica de tais manifestações e como o ativismo popular ("o povo nas ruas") pode mitigar a manipulação do aparelho ideológico do estado e a sua influencia na composição das relações sociais brasileiras.

\section{Do lido ao vivido: A cidade como um espaço de representação, contestação e mudança.}

"Estamos presos ao modelo, somos parte dele".

$\checkmark$ de Vingança

Teoricamente o Brasil é um estado democrático de direito, onde sua população é representada por governantes, que são escolhidos de quatro em quarto anos, com o intuito de gerir o espaço em prol do coletivo, porém o que se observa na prática, é que na realidade o estado se manifesta como um defensor dos interesses do capital, impondo as suas escolhas e transformando as cidades em pontos de concentração de bens e de desigualdades, onde o lucro passa a ser privatizado e os investimentos e prejuízos se tornam socializados, como destaca VAINER", (2002, pág.78): "A cidade é uma mercadoria a ser vendida, num mercado extremamente competitivo, em que outras cidades também estão à venda." (VAINER, 2002, pág.78).

\footnotetext{
${ }^{4}$ Professor do Departamento de Geografia e do Programa de Pós-Graduação em Geografia da Pontifícia Universidade Católica do Rio de Janeiro (PUC-Rio) e professor adjunto da Universidade do Estado do Rio de Janeiro (UERJ).

${ }^{5}$ Economista, sociólogo, Doutor em Desenvolvimento Econômico e Social/Université de Paris I Panthéon/Sorbonne. Professor Titular do IPPUR/UFRJ.
} 
Esse processo de mercadificação da cidade ou "city marketing" revela a potencialização do grande empresariado em conjunto com a esfera governamental, dando origem a um espaço permeado de desigualdades, onde a pobreza passa a ser vista não mais como um problema social, mas sim como uma questão paisagística, tal fato se faz presente na cidade do Rio de Janeiro, com a remoção e desapropriação de moradores de comunidades do centro e de regiões que outrora eram tidas como desvalorizadas pelo poder público. Percebe-se com isso a (re) produção da cidade como um grande negócio, como ressalta $\operatorname{CARLOS}^{6}$ (2005, pág.34):

É através da atuação do Estado que o espaço edificado da metrópole realizando a função da propriedade privada da terra pode ser redefinido pelo processo de desapropriação; momento em que as propriedades mudam de mãos, permitindo a expulsão da população residente dessas áreas para outras, orientando a reocupação com outras formas e funções como imperativo da reprodução. (CARLOS, 2005, pág. 34)

Partindo da perspectiva de que o estado é um dos grandes causadores e fomentadores das diferenças presentes em nossa sociedade, sendo as cidades o grande exemplo dessa dinâmica, as manifestações ocorridas no Brasil demonstram uma forte crise de representação e de simbologia da população brasileira em relação ao aparelho governamental. Mas o que seria essa crise de representação? E quais seriam os seus pontos fundamentais?

Segundo ENAUDEAU (1999, p. 27) "Representar é substituir um ausente, dar-lhe presença e confirmar a ausência". Para ARRETCHE (2011, p. 25), a representação é trazer a presença das atitudes, das ideias, das vontades, dos desejos do outro, como se o outro fosse, e ao mesmo tempo, reafirmando a presença do representante e a ausência do representado. Em relação aos acontecimentos ocorridos no Brasil, a questão da representação se refere à falta de legitimação do povo em relação ao governo, ou seja, o povo deixa de se sentir representado, ou melhor, constatando, o

\footnotetext{
${ }^{6}$ Professora Titular do Departamento de Geografia da Faculdade de Filosofia, Letras e Ciências Humanas da Universidade de São Paulo.
} 
povo passa a entender que jamais ocorreu uma representação efetiva por parte do estado e de seus partidos políticos, criando-se desta forma uma espécie de aversão frente às representações vigentes.

Essa de crise de representação não se relaciona somente a um aumento no valor das tarifas de transportes "públicos" (ideário que a grande mídia tentou impor de inicio a toda população), ela configura uma condição histórica, temporal e espacial muito mais complexa, é uma crise de "identidade," de classes que há tempos se veem subjulgadas a um estado que ratifica a corrupção e estabelece a desigualdade e a alienação a partir dos seus aparatos ideológicos e midiáticos. Na obra "V de Vingança" de Alan Moore (1985) a célebre frase de "V" (personagem central da trama) retrata a relação que tal ativismo possui com a quebra de simbologias que são moldadas pelo estado e impostas a comunidade: "Um símbolo sozinho pode não representar nada, mas se todos se juntam, um símbolo pode significar muito, pode significar a mudança de um país". (Alan Moore, 1985).

Consequentemente, tais atores sociais, percebem-se como foco principal da "mudança" de tais simbologias, ao manifestarem nas ruas a sua insatisfação e o seu repúdio ao forte e meticuloso processo de mercadificação ${ }^{1}$ da vida, desencadeado pela reorganização do capital no espaço da cidade. Entretanto, vale ressaltar que as condições que permeiam a criação de representações e simbologias, jamais se desvinculam da totalidade das relações presentes no espaço, pois é a partir deste que a realidade social se constrói como ressalta SANTOS, (2006, p.82):

A ideologia produz símbolos, criados para fazer parte da vida real, e que frequentemente tomam a forma de objetos. A ideologia é, ao mesmo tempo, um dado da essência e um dado da existência, neste fim do século XX. ...Quando, num lugar, a essência se transforma em existência, o todo em partes e, assim, a totalidade se dá de forma específica, nesse lugar a história real chega também com os símbolos. Desse modo, há objetos que já nascem como ideologia e como realidade ao mesmo tempo. É assim que eles se dão como indivíduos e que eles participam da realidade social. Nessas condições, a totalidade social é formada por mistos de "realidade" e "ideologia". É assim que a história se faz.(SANTOS, 2006, p.82) 


\section{O lugar como expressão do Direito à cidade.}

Ferreira (2011, p.3), ressalta que se o espaço é o lugar da reprodução, é também lugar da contestação, do encontro, da rebeldia, lugar da ação, e é a partir dessa dimensão que devemos conceber o foco principal das manifestações ocorridas no Brasil, pois é diante da "cotidianidade do lugar" que o intermédio e a ressignificação do ser social se perpetua, corroborando com isso para uma real mudança do espaço e de suas futuras relações, como destaca Ferreira (2011, p.17 e 18):

O cotidiano, embora muitas vezes banalizado, já que se expressa por sua miséria e riqueza a partir de eventos triviais, caracteriza-se como a mediação entre a repetição e a criação, entre a alienação e a liberdade, como a clara explicitação da imbricação entre espaço e tempo. As inúmeras possibilidades de apropriação do cotidiano resultam da vivência, da experiência vivida, e têm grande potencial criador, possibilitando a formação e permanência de resistências. Portanto, quando através da apropriação do espaço da cidade reconstruímos a cotidianidade, é possível pensarmos na formação de movimentos que lutem pela emancipação e pela sua transformação. ( FERREIRA,2011, p.17; 18)

A participação popular é fundamental para a formação de uma cidade mais justa e igualitária, pois o espaço que ao mesmo tempo é produto e produtor das relações sociais se concretiza a partir do lugar. Entretanto o que predomina nos dias atuais é a lógica do valor de troca generalizado e sem limites, a cidade sendo moldada como um palco de transações, onde as classes de baixa renda são subjugadas e descartadas do jogo de embelezamento e investimento de um espaço que na teoria pertence á todos, mas que na prática passa a ser apropriado por poucos. E essa ideia de cidade mercantil é implantada em nosso inconsciente a partir da esfera de circulação da mídia, com isso o novo modo de ser e de se viver na cidade está articulado à criação de estilos de vida estimulados pelos meios de comunicação em massa, que se tornam os divulgadores das estratégias de coerção capitalistas. E o lugar, que é a representação mais nítida desse movimento, se torna a ponte de concretização dessa nova mercadoria, como evidencia LEFEBVRE, (1969, p. 79):

O mundo da mercadoria tem sua lógica imanente, a do dinheiro e do valor de troca generalizado sem limites. Uma tal forma, a da troca e a da equivalência, só exprime indiferença diante da forma urbana; ela reduz a simultaneidade e os encontros à forma dos trocadores, e o lugar de encontro ao lugar onde se conclui o contrato ou quase-contrato de troca equivalente: o reduz ao mercado. 
A sociedade urbana, conjunto de atos que se desenrolam no tempo, privilegiando um espaço (sítio, lugar) e por ele privilegiados, altamente significantes e significados, tem uma lógica diferente da lógica da mercadoria. É outro mundo. O urbano se baseia no valor de uso. Não se pode evitar o conflito (LEFEBVRE, 1969: 79).

E a constituição de lugares "mercadificados" transmuta a cidade em um espaço apolítico, metamorfoseando-a, o que impede a criação de uma justiça social, pois inviabiliza a participação popular. Logo, as manifestações que se sucederam no Brasil, e em diversos lugares do mundo configuram uma possibilidade de mudança desse quadro, pois nos leva a reflexão de que por mais que o capital tente se (re) organizar a partir da formação de espaços (des) iguais, sempre haverá uma força de resistência indo contra a esse curso. E com o advento e a utilização das redes sociais, essa força adquiriu um impulso ainda maior, burlando a manipulação da mídia e contrariando as expectativas dos governantes, comprovando mais uma vez a força do lugar, e da mobilização popular, seja ele geográfico ou virtual, é um lócus privilegiado da ação subversiva e que ultrapassa em muito o poder coercitivo do Estado na criação de consenso. 


\section{Considerações Finais}

A conjuntura a qual estamos inseridos leva a uma alienação (re) produzida como materialidade no cotidiano. Nesta perspectiva se é possível observar como a homogeneização do espaço vem suprimindo quase todas as particularidades e vozes de resistência do lugar, assim como sua identidade e cultura. $\mathrm{Na}$ imposição de uma ordem global sobre a ordem do lugar, e na criação de símbolos que são verdadeiros monumentos a barbárie (Benjamim, 1994) que expressam apenas a um padrão de cultura de elite e minoritária da sociedade, sendo assim quando um manifestante destrói um monumento publico em uma manifestação, o faz porque tal monumento de nenhuma forma tem algum grau de pertencimento ou faz parte da identidade deste individuo.

Porém ao considerarmos o espaço como um produto e produtor das relações sociais que são produzidas em determinado contexto histórico, ele (espaço) pode ser produzido de outra maneira, uma que busque a ser mais igualitária, e que rompa com os padrões vigentes de produção do espaço que está atrelado diretamente ao modelo capitalista de produção, mas que apenas pode ser alcançado através das brechas encontradas no próprio capitalismo. Onde observa-se no Brasil hoje um momento único em que o citadinos se viram tão agredidos em seu direito básicos (transporte, educação, saúde, moradia) conjuntamente com uma evidente crise nas representações, e um levante das minorias que se vem a muito tempo reprimidas, houve um ponto de ruptura que serviu como estopim de uma revolução, fazendo que cotidiano deixe de ser banal e passe a ser o local da indignação e luta individuas de direitos, mas também representando ideais coletivos da população de cada lugar. Esse movimento que foi extremamente potencializado pela utilização das redes sociais que possibilitam a rápida disseminação de informação que auxiliaram a organização do movimento. E que chegou/chega a ter dimensões tão grandiosas que Estado viu ameaçado ao ponto de agir de formas extremamente violentas e coercitivas, chegando a chamar os manifestantes que não se comportavam segundo os padrões aceitáveis 
pelo Estado de vândalos, ladrões e desocupados, em um claro intuito de deslegitimar o movimento.

Por fim acreditamos que a criação de um espaço mais humano e igualitário perpassa diretamente por uma revolução que só pode se dar no cotidiano, a partir da mobilização das classes populares em um movimento continuo de revolução/subversão a lógica global imposta e vigente. Até onde o eco das manifestações no Brasil e 2013 chegarão só o tempo poderá afirmar, mas com certeza esse momento pode reafirmar a força imanente à população. 


\section{REFERÊNCIAS}

ARRETCHE, Zaira Maria, A Ideia De Representação Nas Teorias Democráticas E Litista, Republicana E Democracia Radical. Universidade Federal De Pelotas Instituto De Sociologia E Política Programa De Pós-Graduação Em Ciências Sociais, Pelotas, 2011

BENJAMIN, Walter. Sobre o conceito de História. In: Magia e técnica, arte e política: ensaios sobre literatura e história da cultura. São Paulo: Brasiliense, 1994.

CARLOS, Ana Fani Alessandri. A reprodução da cidade como negócio. In: Carlos, A. F. A.; Carreras, C.. (Org.). Urbanização e Mundialização. Estudos sobre a metrópole. São Paulo: Editora Contexto, 2004, v. , p. 29-37.

ENAUDEAU, Corinne. La presencia em la ausencia. In: La paradoja de la representación. Buenos Aires: Paidós, 1999.

FERREIRA, Alvaro. Produção e apropriação do espaço: em busca da utopia do sujeito da transformação. O projeto de revitalização da área portuária do Rio de Janeiro. In: IX Encontro Nacional da ANPEGE, 2011, Goiânia. Anais do IX Encontro Nacional da ANPEGE. Goiânia, 2011.

LEFEBVRE, Henri. A revolução urbana. Belo Horizonte: UFMG, 2002.

LEFEBVRE, Henri. A La production de l'espace. 4. ed. Paris: Anthropos, 2000.

LEFEBVRE, Henri. O direito à cidade. São Paulo: Documentos, 1969.

SANTOS, Milton. A Natureza do Espaço: Técnica e Tempo, Razão e Emoção /- 4. ed. 2. reimpr. - São Paulo: Editora da Universidade de São Paulo, 2006. - (Coleção Milton Santos; 1)

MOORE Alan, V de Vingança, Warner Bros, 2006, disponivel em: http://www.filmesonlinegratis.net/assistir-v-de-vinganca-dublado-online.htm 
VAINER, Carlos Bernardo Pátria, empresa e mercadoria. In ARANTES, O. B. F., A cidade do pensamento único - Petrópolis, Vozes, 2000. 